\title{
Near-limit propagation of gaseous detonations in thin annular channels
}

\author{
Yuan $\mathrm{Gao}^{1}$, Hoi Dick $\mathrm{Ng}^{2 \dagger}$, John H.S. Lee ${ }^{1}$ \\ ${ }^{1}$ Department of Mechanical Engineering \\ McGill University, Montréal, Québec, H3A 2K6, Canada \\ ${ }^{2}$ Department of Mechanical and Industrial Engineering \\ Concordia University, Montréal, Québec, H3G 1M8, Canada
}

Corresponding Author

Department of Mechanical and Industrial Engineering

Concordia University

1455 de Maisonneuve Blvd. West

Montréal, Québec, H3G 1M8, Canada

e-mail: hoing@encs.concordia.ca

Tel.: +1 (514) 848-2424 (ext. 3177)

Fax: +1 (514) 848-3175

Revised manuscript submitted to Shock Waves Journal

June 2015 


\title{
Near-limit propagation of gaseous detonations in thin annular channels
}

\begin{abstract}
New results on the near-limit behaviors of gaseous detonations in thin annular channels are reported in this paper. The annular channels of thicknesses $3.2 \mathrm{~mm}$ and $5.9 \mathrm{~mm}$ are made by inserting smaller diameter tubes of $44.4 \mathrm{~mm}$ and $39.0 \mathrm{~mm}$ into a larger 50.8-mm diameter outer tube. The length of each annular channel is $2.0 \mathrm{~m}$. Detonations are initiated in a steel driver tube where a small volume of a sensitive $\mathrm{C}_{2} \mathrm{H}_{2}+2.5 \mathrm{O}_{2}$ mixture is used to facilitate detonation initiation. A 2-m length of circular tube with $50.8-\mathrm{mm}$ diameter precedes the annular channel so that a steady Chapman-Jouguet (CJ) detonation is established prior to entering the annular channel. Four detonable mixtures of $\mathrm{C}_{2} \mathrm{H}_{2}+2.5 \mathrm{O}_{2}+85 \% \mathrm{Ar}, \mathrm{C}_{2} \mathrm{H}_{2}+$ $2.5 \mathrm{O}_{2}+70 \% \mathrm{Ar}, \mathrm{C}_{3} \mathrm{H}_{8}+5 \mathrm{O}_{2}$ and $\mathrm{CH}_{4}+2 \mathrm{O}_{2}$ are used in the present study. Photodiodes spaced at $10 \mathrm{~cm}$ throughout the length of both annular channel and circular tube are used to measure the detonation velocity. In addition, smoked foils are inserted into the annular channel to monitor the cellular structure of the detonation wave. The results show that well within the limits the detonation wave propagates along the channel with a small local velocity fluctuation and an averaged global velocity can be deduced. The averaged detonation velocity has a small deficit of $5-15 \%$ far from the limits and rapidly drops to $0.7 V_{C J}-0.8 V_{C J}$ when the onset of limit occurs. Subsequently, the fluctuation of local velocity also increases with decreasing initial pressure approaching the limit. No galloping detonations are observed for both stable and unstable mixtures in annular channels. The present study also confirms that single-headed spinning detonation occurs at the limit as in circular tube rather than the up and down "zig zag" mode in a two-dimensional rectangular channel.
\end{abstract}

Keyword: Annular channels; Local velocity fluctuation; Detonation limits; Single-headed spinning detonation; Cellular structure 


\section{Introduction}

As the detonation limit is approached, the steady propagation velocity decreases typically to about $80-90 \%$ of the Chapman-Jouguet (CJ) value before failure [1-3]. The fluctuation of the detonation velocity also increases as the limit is approached and if galloping detonation precedes failure, the velocity fluctuation can be as large as $40-150 \%$ of the CJ value [2, 4-6]. The detonation cell size also increases towards the limit from multi-headed detonation to single-headed spinning detonation. The above mentioned characteristics are typical near-limit phenomena. Different detonable mixtures and tube geometries exhibit slightly different nearlimit behavior [7-14]. To understand the limit phenomena, an extensive study covering a spectrum of mixture properties and tube geometries is required. Almost all studies of detonation limits have been carried out in circular tubes. Thus it is of interest to explore other tube geometries. Limited studies have been carried out in thin rectangular channels (e.g., [1517]). However, their investigations are focused mainly on the velocity deficit. To avoid threedimensional effects of the side walls in rectangular channels, near-limit propagation of detonations in annular channels had been carried out in the study by Chao et al. [18]. Detonation limits in the annular channels in so-called "stable" mixtures of $\mathrm{H}_{2} / \mathrm{O}_{2}$ and $\mathrm{C}_{2} \mathrm{H}_{2} / \mathrm{O}_{2}$ with high percentage of argon dilution were investigated. However, their emphasis was on velocity deficits in near-limit conditions rather than on the limit phenomena itself. Furthermore the length of their annular channel used was rather short (i.e., $0.36 \mathrm{~m}$ ) to adequately investigate the near-limit behavior. In a later study of detonation propagation in annular channels by Lee et al. [19], a longer annular channel of $1.5 \mathrm{~m}$ was used and a wider range of detonable mixtures covering both "stable" and "unstable" detonations was studied. However, the focus of that study was again on the near-limit velocity deficit rather than on the near-limit phenomena of the detonation. The present study is essentially a continuation of 
our previous investigation. An even longer channel of $2.0 \mathrm{~m}$ is used to permit the propagation of the detonation to be observed over a longer travel. With an annular thickness of $w=3.2$ $\mathrm{mm}$ and $5.9 \mathrm{~mm}$, a propagation length of about 333 to 625 thicknesses can be obtained. Two "stable" (highly regular cell pattern) and "unstable" mixtures (highly irregular cell pattern) were used. Detailed velocity measurements were made via optical photodiodes located along the length of the annular channel and the circular tube. In addition, smoked foils were simultaneously used to record the detonation cellular structure as the limits are approached.

\section{Experimental Details}

As in our previous investigations $[18,19]$, the annular channel is obtained by inserting a smaller diameter tube " $d$ " into a larger diameter tube " $D$ ". The thickness of the annular channel $w$ is thus $w=(D-d) / 2$. The inner diameter of the larger tube $D$ is $50.8 \mathrm{~mm}$ and smaller diameter tubes are used to give annular channel thicknesses of $3.2 \mathrm{~mm}$ and $5.9 \mathrm{~mm}$. Thin steel blades (50-mm long and 1-mm thick) are used to support the smaller diameter tube to permit a constant thickness throughout the length of the annular channel. The leading edge of the smaller inner diameter tube is sharpened and chamfered to reduce the interference with the flow or to prevent creating any significant wave activities from affecting the propagation of the detonation wave toward the test section of the annular channel. The inner smaller diameter tube and outer larger diameter tube are coaxial. Both ends of the smaller inner diameter and larger outer diameter tubes are connected together by blind flanges. The length of the annular channel is $2.0 \mathrm{~m}$ and a circular tube of $2.0 \mathrm{~m}$ is also connected preceding the annular channel to by-pass the transient effect due to the initiation process and to ensure a steady detonation is first established prior to its entrance into the annular section. The detonation is initiated in a $1.3-\mathrm{m}$ long steel driver section in a sensitive mixture of stoichiometric $\mathrm{C}_{2} \mathrm{H}_{2} / \mathrm{O}_{2}$ and the detonation is then transmitted into the less sensitive test 
mixture. Fiber optics of $2 \mathrm{~mm}$ in diameter terminating in photodiodes (IF-95OC) are spaced $10 \mathrm{~cm}$ apart along the entire length of both the circular tube and the annular channel. The fall time of the photodiode is 5 ns. A schematic of the experimental setup is shown in Fig. 1a. Typical output from the optical detectors is also shown in Fig. 1b. The theoretical CJ velocity is calculated by the CEA program [20]. Pre-mixed mixtures of $\mathrm{C}_{2} \mathrm{H}_{2}+2.5 \mathrm{O}_{2}+85 \% \mathrm{Ar}, \mathrm{C}_{2} \mathrm{H}_{2}$ $+2.5 \mathrm{O}_{2}+70 \% \mathrm{Ar}, \mathrm{C}_{3} \mathrm{H}_{8}+5 \mathrm{O}_{2}, \mathrm{CH}_{4}+2 \mathrm{O}_{2}$ are used. The argon-diluted mixtures represent "stable" mixtures with regular cell pattern and a piece-wise laminar detonation front structure $[21,22]$. The undiluted mixtures are called "unstable" with highly irregular cell pattern [2325]. In addition, smoked foils are also inserted into the annular channel to observe the cellular structure of the detonation wave. The smoked foils were made of thin $(300 \mu \mathrm{m})$ plastic film covered with uniform soot. Before each shot of the experiment, the smoked foils were carefully installed on the outside wall of the inner tube and the cellular detonation patterns were registered along the length of detonation travel. The cell size of the detonation can then be measured following the procedures detailed in [1]. For unstable mixtures, the observed pattern is highly irregular and thus, to obtain a single representative value for the cell size from an irregular smoked foil pattern, more than one foil sample are considered to provide a reliable value for the cell size measurement for unstable mixtures.

\section{Results and Discussions}

The variation of the local detonation velocity along the length of the annular channel for the various mixtures and different annular thicknesses (of $3.2 \mathrm{~mm}$ and $5.9 \mathrm{~mm}$ ) is summarized in Figs. 2 to 5. The local velocities along the test section are obtained from two adjacent probes. The velocity in the 50.8-mm diameter circular tube prior to the detonation entering the annular channel is also plotted to show that the detonation propagation is not affected by the initiation process. In general, the detonation velocity in the annular channel is slightly less 
than the corresponding value in the circular tube due to more significant wall effect. Apparent from the trend of these plots, the fluctuation of the local velocity increases with decreasing the initial pressure. It may be worth noting that near the limits, it is possible that the luminosity of the detonation zone has a spatial inhomogeneity leading to significant variation of the results. Therefore, in order to ensure reliable results, experiments at the same initial conditions with different position of photodiode sensors were repeated several times. In addition, other measurement methods, for example, using ion probes and smoked foils are considered. From the comparison of these different measurements, it is observed that the data does not have a large scatter between different shots. This thus implies that near the limits the position of the sensors does not have a significant effect on the detonation wave velocity measurement and the velocity data is properly recorded using the present diagnostics, as used in several other studies in the literature $[5,26,27]$.

As the mixture pressure approaches the limiting value, the detonation propagates for a short distance and subsequently the velocity fluctuates and drops rapidly. For the stable mixtures of $\mathrm{C}_{2} \mathrm{H}_{2}+2.5 \mathrm{O}_{2}+85 \% \mathrm{Ar}$ and $\mathrm{C}_{2} \mathrm{H}_{2}+2.5 \mathrm{O}_{2}+70 \% \mathrm{Ar}$, the local velocity drops to typical values as low as $0.4 V_{\mathrm{CJ}}$. Afterward, no signals were recorded at the subsequent optical probes in the annular channel due to the insufficient luminosity, indicating a complete failure of the unsteady detonation wave. For the unstable mixtures of $\mathrm{C}_{3} \mathrm{H}_{8}+5 \mathrm{O}_{2}$ and $\mathrm{CH}_{4}+2 \mathrm{O}_{2}$, the fluctuations of the local velocity are large, and also the velocity prior to complete failure in the annular channel is found to be lower (of the order of $0.2 V_{\mathrm{CJ}}$ ) as compared to $0.4 V_{\mathrm{CJ}}$ for the stable mixtures. The latter can be due to the stronger instability in unstable reaction zone which maintains a lower velocity propagation and chemical reactivity with enough luminosity detected by the optical probes. A remark should be made that for the $\mathrm{CH}_{4}+2 \mathrm{O}_{2}$ mixture in 5.9-mm thick annular channel, the fluctuation of local detonation velocity 
becomes well apparent at $5 \mathrm{kPa}$ (see Fig.5a). Limiting pressure for the $\mathrm{CH}_{4}+2 \mathrm{O}_{2}$ mixture in 5.9-mm thick annular channel could arrive by further decreasing the initial pressure. However, for the $\mathrm{CH}_{4}+2 \mathrm{O}_{2}$ mixture in a $50.8-\mathrm{mm}$ diameter circular tube, the limiting pressure is very close to $4.5 \mathrm{kPa}$ as obtained from the previous study [5]. Hence, if the initial pressure is further reduced to slightly below $4.5 \mathrm{kPa}$, limit can already be attained in the circular tube before the annular channel section. There remains a possibility that if an appropriately larger diameter circular tube is available to maintain the required initial condition, detonation limits can be properly identified for the $\mathrm{CH}_{4}+2 \mathrm{O}_{2}$ mixture in 5.9-mm thick annular channel. Further, a longer annular channel may be ideal to observe the complete failure particularly for unstable mixtures like $\mathrm{CH}_{4}+2 \mathrm{O}_{2}$. This remains inconclusive and future work is thus necessary to identify quantitatively limits for the $\mathrm{CH}_{4}+2 \mathrm{O}_{2}$ mixture in the 5.9-mm thick annular channel.

It is also important to note that in all the present results, no galloping detonation wave is clearly observed for unstable mixtures even in the smaller annular channel of $w=3.2 \mathrm{~mm}$. Although one may argue that the length of annular channel used is not long enough to observe the cyclic fluctuation of galloping detonations, there are indeed no indications of the onset of the galloping fluctuations. As shown in [6], the typical wavelength $L$ of galloping detonation in circular tubes for various unstable mixtures is of the order of $L / D \approx O[350]$. More specifically, as shown in [26], for $D=6 \mathrm{~mm}$ diameter circular tube the wavelength $L$ of one cycle of galloping detonation is approximately $250 \mathrm{D}$. For the annular channels used in this paper, it is more reasonable to determine the hydraulic diameter as a characteristic dimension to compare the detonation propagation in annular channels with that in circular tubes. In the present study, the corresponding hydraulic diameter, $\left(D_{H}=4 \times \frac{\pi\left(D^{2}-d^{2}\right)}{4} / \pi(D+d)=2 w\right)$, is $D_{\mathrm{H}}=6.4 \mathrm{~mm}$ for $w=3.2 \mathrm{~mm}$ annular channel, which is close to $6 \mathrm{~mm}$ (the diameter value of $D=6 \mathrm{~mm}$ circular tube). Hence, it is 
reasonable to compare the local velocity variation of the detonation wave in 3.2-mm annular channel with the corresponding evolution in similar diameter circular tube of $D=6 \mathrm{~mm}$ to determine whether or not galloping detonation exists in annular channel geometry. From the results shown in Fig. $4 \mathrm{~b}$ for the $\mathrm{C}_{3} \mathrm{H}_{8}+5 \mathrm{O}_{2}$ mixture, it is found that the detonation wave velocity decays continuously after entering the annular channel at $P_{0}=2 \mathrm{kPa}$. The length of the decaying section is of about $L / D_{\mathrm{H}}=312$. If a galloping mode exhibits in annular detonation, the value of $L / D_{\mathrm{H}}$ of the "decaying phase" should be much shorter than that of one typical wavelength of galloping detonation. However, the present result shows that the value of $L / D_{\mathrm{H}}$ of this "decaying phase" in annular channel is significantly larger than the $L / \mathrm{D}$ $=250$ of one cycle wavelength of typical galloping detonation. Furthermore, for typical galloping detonation the lowest velocity is of about $V=0.4 V_{\mathrm{CJ}}$. Whereas, in the annular channel, again the lowest velocity decays to about $V=0.2 V_{\mathrm{CJ}}$ which is smaller than the typical minimum velocity of galloping detonation before its re-acceleration in the cycle. Similar phenomena are also observed for detonation wave in annular channel when the initial pressure is made even lower than the limiting pressure. Therefore, all these observations indicate that there is no apparent galloping detonation near the limits in annular channel and galloping detonation is found to be dependent on the tube geometry. It is also worth noting that in the present study, the ratio of the length to thickness of 5.9 and 3.2-mm annular channels, $L / w$, is equal to 333 and 625 , respectively (or equivalently, the ratios of the length to hydraulic diameter $L / D_{\mathrm{H}}$ are 167 and 313). So the channel length should be long enough to observe at least one cycle of galloping detonations in annular channels, if these exist. Nevertheless, more experiments with longer channel length are no doubt desirable in the future work to show conclusively this present observation.

The results shown in Figs. 2-5 give the local velocity during the wave propagation. The 
local velocity fluctuations are indeed useful to provide a qualitative idea of the near limit behavior. Nevertheless, close to limit, the fluctuation of the local velocity can be quite significant and it is often not meaningful to obtain a global averaged value of these local velocities. Since the onset of detonation limit is generally indicated by a continuous velocity deficit as the initial pressure decreases, it is thus useful to define a minimum steady velocity just prior to failure when the trajectory still indicates a steady self-sustained detonation without decay [3]. This also serves to define the detonation limit as the critical condition past the existence of this steady minimum propagating velocity. The steady velocity in the annular channel with initial pressures for the four tested mixtures is shown in Figs. 6 to 9. Only the steady velocity (or an overall averaged velocity with less than 5\% local fluctuation deduced from the local velocity measurement) when the detonation can propagate the entire length of the annular channel is considered. In general, the propagation of detonation waves should be governed by the initial pressure of the mixture and the dimension of the boundary geometry. Also, decreasing the initial pressure will result in the increase of the detonation cell size or equivalently, the decrease of the sensitivity of the mixture. To this end, the hydraulic diameter representing the physical length scale of the boundary condition should be correlated with the length scale of detonation structure characterized by the cell size $\lambda$. Hence, a normalized parameter $D_{\mathrm{H}} / \lambda$ is used to analyze the propagation of detonation wave in annular channel. The ratio $D_{\mathrm{H}} / \lambda$ can be considered as an appropriate dimensionless parameter that defines the detonation limits. Well within the limits, the velocity is close to the theoretical CJ value with a few percent velocity deficits. The detonation velocity decreases slowly with decreasing initial pressure (or $D_{\mathrm{H}} / \lambda$ ). Whereas as the limits are approached, the detonation velocity deviates from the CJ value and a sharp decrease in the velocity is observed. For the stable mixtures of $\mathrm{C}_{2} \mathrm{H}_{2}+2.5 \mathrm{O}_{2}$ with $85 \%$ and $70 \%$ argon dilution, the minimum steady velocity in 
the annular channel is found to be about $0.8 V_{\mathrm{CJ}}$ at the limits. For the unstable mixtures $\mathrm{C}_{3} \mathrm{H}_{8}+$ $5 \mathrm{O}_{2}$ and $\mathrm{CH}_{4}+2 \mathrm{O}_{2}$, the minimum steady velocity at the limits is about $0.7 V_{\mathrm{CJ}}$, slightly lower than that for stable mixtures. Past their corresponding minimum steady velocity, the variation of the detonation velocity is found to be larger for the unstable mixtures, as discussed in the previous section. It is also interesting to note that when the hydraulic diameter for the annular channel $\left(D_{\mathrm{H}}=2 w\right)$ is used as shown in Figs. 6 to 9, the velocity curves are found to collapse to a single curve indicating that the hydraulic diameter provides a more appropriate length scale than the channel thickness " $w$ ".

The critical values of $D_{\mathrm{H}} / \lambda$ for detonation limits in annular channels are tabulated in Table 1. In this table, the critical value of $D_{\mathrm{H}} / \lambda$ for each annular channel thickness corresponds to the minimum steady velocity as determined above, thus defining the detonation limits. For clarity, these critical values of $D_{\mathrm{H}} / \lambda$ are marked in Figs. 6 to 9 . The corresponding values of $d / \lambda$ for circular tubes are also shown in Table 1 for comparison and equivalently, a steady detonation wave cannot be achieved in circular tubes when the values of $d / \lambda$ are smaller than these critical values. As observed in previous studies [18, 19], it is found that single-headed spinning detonations were also observed in annular channels at the limit rather than the expected so- called "zig zag" mode in two-dimensional rectangular channels [28] (analogous to spinning detonations in circular tubes). Thus, it again supports that the hydraulic diameter " $D_{\mathrm{H}}$ " would be more appropriate than using the thickness of the annular channel " $w$ " for the $\lambda$ correlation. If we consider for single-headed spins that $\pi D \approx \lambda$, or $D / \lambda \approx 1 / \pi=0.318$ [1], then the results in Table 1 appear to agree roughly with this single-headed spin criterion even for annular channels except perhaps for the particular case of unstable $\mathrm{CH}_{4}+2 \mathrm{O}_{2}$ detonations, where the critical value for $D_{\mathrm{H}} / \lambda$ for annular detonations appears to be much lower than for the other mixtures. However, in circular tubes, the critical value for $\mathrm{CH}_{4}+2 \mathrm{O}_{2}$ is found to be 
in accord with the $D / \lambda \approx 1 / \pi$ criterion. Apart from the higher degree of uncertainty associated with the cell size determination of $\mathrm{CH}_{4}+2 \mathrm{O}_{2}$ and the use of the hydraulic diameter for the scaling, the lower critical value of $D_{\mathrm{H}} / \lambda$ for annular detonations may be due to geometry of the wave front of the single-headed detonation front. The relatively less curved front, hence smaller losses, for single-headed spinning detonations in annular channels could extend the range of the existence of single-headed detonation than the one in circular tubes.

Typical smoked foil records for detonations in annular channels are shown in Fig. 10. The smoked foils are taken near the end of the annular channel. Although in the experiments, the width of the foil used correspond to the entire circumference of the inner tube of the annular channel, only the central portion is shown in Fig. 10 as the edges are smeared where removing the foil from the tube. In Fig. 10a, detonations in $\mathrm{C}_{2} \mathrm{H}_{2}+2.5 \mathrm{O}_{2}+70 \% \mathrm{Ar}$ are illustrated. For initial pressures far from the limits, multi-headed detonations are observed (e.g., $P_{0}=12 \mathrm{kPa}$ ). The cell size increases progressively towards the limits at about $6 \mathrm{kPa}$. For unstable $\mathrm{CH}_{4}+2 \mathrm{O}_{2}$ (Fig.10b), the cellular pattern is highly irregular at high initial pressure (e.g., $P_{0}=25 \mathrm{kPa}$ ), but the cell size also increases with decreasing initial pressure.

Figures 11 and 12 show smoked foils at the limits in the annular channel. A long smoked foil that spans the entire length of the annular channel is used. In Fig. 11, a multi-headed detonation is first observed at the entrance to the annular channel which then decays rapidly to a double-headed detonation and eventually no cellular structure can be observed when the detonation fails. Figure 12 shows the decays to a single-headed spinning detonation and eventually fails towards the end of the annular channel in $\mathrm{C}_{3} \mathrm{H}_{8}+5 \mathrm{O}_{2}$. Note that the width of the foil corresponds to the circumference of the smaller diameter insert of the annular channel. At the limits, the detonation is observed to be a single-headed spinning detonation which propagates around the circumference of the annular channel rather than the up and down "zig 
zag" mode as one would expect for a two-dimensional rectangular channel. This observation is in accord with our previous investigation of limits for annular detonations [19]. Thus, the occurrence of a single-headed spinning detonation in annular channels at the limits is clearly demonstrated. Again no galloping detonations were observed in annular channels in the present study, which is in accord with our previous investigations $[18,19]$. The observation of the single-headed circumference mode indicates a certain "robustness" of the detonation wave which always tends towards the larger length scale to perform a lower frequency mode to maintain self-sustained propagation. This is not surprising since even for a spinning detonation in a circular tube, the strong Mach stem of the "spinning head" occurs near the tube wall and attenuates rapidly away from the wall towards the tube axis.

\section{Conclusions}

The present study of near-limit detonations in annular channels in both highly argon-diluted "stable" mixtures of $\mathrm{C}_{2} \mathrm{H}_{2}+2.5 \mathrm{O}_{2}+85 \% \mathrm{Ar}, \mathrm{C}_{2} \mathrm{H}_{2}+2.5 \mathrm{O}_{2}+70 \% \mathrm{Ar}$ and "unstable" mixtures of $\mathrm{C}_{3} \mathrm{H}_{8}+5 \mathrm{O}_{2}, \mathrm{CH}_{4}+2 \mathrm{O}_{2}$ indicates that away from the limits the detonation propagates at relatively steady velocity with small local velocity fluctuations. The minimum steady detonation velocity is found to be about $0.8 V_{\mathrm{CJ}}$ for stable mixtures and $0.7 V_{\mathrm{CJ}}$ for unstable mixtures when the onset of detonation limits occurs. As the limits is approached the fluctuation increases gradually. Nevertheless, no galloping detonation is observed near the limits for both stable and unstable mixtures, which may indicate that the tube geometry plays an important role in the formation of galloping detonation. From the analysis of the critical values of $D_{\mathrm{H}} / \lambda$, it seems that the hydraulic diameter " $D_{\mathrm{H}}$ " would be more appropriate length scale than the thickness of annular channel " $w$ ". The present study also indicates that the lowest mode prior to failure is that of a single-headed spinning detonation as in circular tubes rather than the up and down "zig zag" mode for the two-dimensional channels. The results of 
the present investigation also suggest that a thin annular channel does not behave the same as a rectangular channel of large aspect ratio $L / w$.

\section{Acknowledgement}

This work is supported by the Natural Sciences and Engineering Research Council of Canada (NSERC).

\section{References}

[1] Lee, J.H.S.: The Detonation Phenomenon. Cambridge University Press, New York (2008).

[2] Vasil'ev, A.A.: Near-limiting regimes of gaseous detonation. Combust. Expl. Shock Waves 23(3), 358-364 (1987).

[3] Gao, Y., Ng, H.D. and Lee, J.H.S.: Minimum tube diameters for steady propagation of gaseous detonations. Shock Waves 24(4), 447-454 (2014).

[4] Ul'yanitskii, V.Y.: Galloping mode in a gas detonation. Combust. Expl. Shock Waves 17 (1), 93-97 (1981).

[5] Gao, Y., Lee J.H.S. and Ng, H.D.: Velocity fluctuations near the detonation limits. Combust. Flame 161(11), 2982-2990 (2014).

[6] Gao, Y., Lee J.H.S. and Ng, H.D.: Experimental characterization of galloping detonations in unstable mixtures. Combust. Flame 162(6), 2405-2413 (2015).

[7] Haloua, F., Brouillette, M., Lienhart, V. and Dupré, G.: Characteristics of unstable detonations near extinction limits. Combust. Flame 122(4), 422-438 (2000).

[8] Lee, J.J. Dupré, G., Knystautas R. and Lee, J.H.S.: Doppler interferometry study of unstable detonations. Shock Waves 5(3), 175-181 (1995). 
[9] Manzhalei, V.I.: Low-velocity detonation limits of gaseous mixtures. Combust. Expl. Shock Waves 35(3), 296-302 (1999).

[10] Jackson, S., Lee, B.J., Huang, W., Pintgen, F., Karnesky, J., Liang, Z. and Shepherd, J.E.: Experimental detonation propagation under high loss conditions. Proc. $22^{\text {nd }}$ Int. Colloq. Dynamics Expl. Reac. Sys., Minsk, Belarus (2009).

[11] Camargo, A., Ng, H.D., Chao, J. and Lee, J.H.S.: Propagation of near-limit gaseous detonations in small diameter tubes. Shock Waves 20(6), 499-508 (2010).

[12] Vasil'ev, A.A.: Quasi-steady regimes of wave propagation in active mixtures. Shock Waves 18(4), 245-253 (2008).

[13] Wu, M.H. and Wang, C.Y.: Reaction propagation modes in millimeter-scale tubes for ethylene/oxygen mixtures. Proc. Combust. Inst. 33(2), 2287-2293 (2011).

[14] Ishii, K. and Gronig, H.: Behavior of detonation waves at low pressure. Shock Waves 8(1), 55-61 (1998).

[15] Ishii, K., Itoh, K. and Tsuboi, T.: A study on velocity deficits of detonation waves in narrow gaps. Proc. Combust. Inst. 29(2), 2789-2794 (2002).

[16] Ishii, K. and Monwar, M.: Detonation propagation with velocity deficits in narrow channels. Proc. Combust. Inst. 33(2), 2359-2366 (2011).

[17] Monwar, M., Yamamoto, Y., Ishii, K. and Tsuboi, T.: Detonation propagation in narrow gaps with various configurations. J. Therm. Sci. 16(3), 283-288 (2007).

[18] Chao, J., Ng, H.D. and Lee, J.H.S.: Detonation limits in thin annular channels. Proc. Combust Inst. 32(2), 2349-2354 (2009).

[19] Lee, J.H.S., Jesuthasan, A. and Ng, H.D.: Near limit behavior of the detonation velocity. Proc. Combust. Inst. 34(2), 1957-1963 (2013).

[20] Mcbride, B.J. and Gordon, S.: Computer Program for Calculation of Complex Chemical 
Equilibrium Compositions and Applications. RP-1311, NASA Reference Publication, Cleveland (1996).

[21] Radulescu, M.I.: The Propagation and Failure Mechanism of Gaseous Detonations: Experiments in Porous- Walled Tubes. Ph.D. thesis, McGill University, Canada (2003).

[22] Ng, H.D. and Zhang, F.: Detonation Instability. In: Zhang, F. (Ed.), Shock Waves Science and Technology Library, Vol. 6: Detonation Dynamics, Springer, Berlin Heidelberg, Chap. 3 (2012).

[23] Pintgen, F., Eckett, C.A., Austin, J.M. and Shepherd, J.E.: Direct observations of reaction zone structure in propagating detonations. Combust. Flame 133(3), 211-220 (2003).

[24] Radulescu, M.I. and Lee, J.H.S.: The failure mechanism of gaseous detonations: experiments in porous wall tubes. Combust. Flame 131(1), 29-46 (2002).

[25] Radulescu, M.I., Ng, H.D., Lee, J.H.S. and Varatharajan, B.: The effect of argon dilution on the stability of acetylene-oxygen detonations. Proc. Combust. Inst. 29(2), 2825-2831 (2002).

[26] Susa, A., Hasegawa, S., Yokoyama, H. and Endo, T.: Oscillating propagation of nearlimit detonations of $\mathrm{CH}_{4} / \mathrm{O}_{2}$ system in a small diameter tubes. Proc. $23^{\text {rd }}$ Int. Colloq. Dynamics Expl. Reac. Sys., Irvine, US (2011).

[27] Kitano, S., Fukao, M., Susa, A., Tsuboi, N., Hayashi, A. K. and Koshi, M.: Spinning detonation and velocity deficit in small diameter tubes. Proc. Combust. Inst. 32(2), 2355-2362 (2009).

[28] Dove J.E. and Wagner, H. Gg.: A photographic investigation of the mechanism of spinning detonation. Proc. Combust. Inst. 8(1), 589-600 (1961). 


\section{Table captions}

Table 1. Critical value of $D_{\mathrm{H}} / \lambda$ and $d / \lambda$ in annular channels and circular tubes

Table 1. Critical value of $D_{\mathrm{H}} / \lambda$ and $d / \lambda$ in annular channels and circular tubes

\begin{tabular}{ccccccc}
\hline Mixtures & \multicolumn{5}{c}{$D_{\mathrm{H}} / \lambda$ and $d / \lambda$} \\
& $w=5.9 \mathrm{~mm}$ & $w=3.2 \mathrm{~mm}$ & $d=3.2 \mathrm{~mm}$ & $d=12.7 \mathrm{~mm}$ & $d=31.7 \mathrm{~mm}$ & $d=50.8 \mathrm{~mm}$ \\
\hline $\mathrm{C}_{2} \mathrm{H}_{2}+2.5 \mathrm{O}_{2}+85 \% \mathrm{Ar}$ & 0.18 & 0.28 & 0.23 & 0.23 & 0.21 & 0.26 \\
$\mathrm{C}_{2} \mathrm{H}_{2}+2.5 \mathrm{O}_{2}+70 \% \mathrm{Ar}$ & 0.22 & 0.24 & 0.19 & 0.17 & 0.16 & 0.17 \\
$\mathrm{C}_{3} \mathrm{H}_{8}+5 \mathrm{O}_{2}$ & 0.14 & 0.22 & 0.39 & 0.35 & 0.33 & 0.22 \\
$\mathrm{CH}_{4}+2 \mathrm{O}_{2}$ & -- & 0.08 & 0.41 & 0.37 & 0.32 & 0.30 \\
\hline
\end{tabular}

$D_{\mathrm{H}}$ is the hydraulic diameter of annular channel

$w$ is the thickness of annular channel

$d$ is the diameter of circular tube 


\section{Figures captions}

Fig.1. A schematic of the experimental apparatus and sample signals from the optical detectors

Fig.2. Normalized detonation velocity in 5.9 and 3.2- $\mathrm{mm}$ annular channel as a function of initial pressure for $\mathrm{C}_{2} \mathrm{H}_{2}+2.5 \mathrm{O}_{2}+85 \% \mathrm{Ar}$

Fig.3. Normalized detonation velocity in 5.9 and 3.2-mm annular channel as a function of initial pressure for $\mathrm{C}_{2} \mathrm{H}_{2}+2.5 \mathrm{O}_{2}+70 \% \mathrm{Ar}$

Fig.4. Normalized detonation velocity in 5.9 and 3.2- $\mathrm{mm}$ annular channel as a function of initial pressure for $\mathrm{C}_{3} \mathrm{H}_{8}+5 \mathrm{O}_{2}$

Fig.5. Normalized detonation velocity in 5.9 and 3.2-mm annular channel as a function of initial pressure for $\mathrm{CH}_{4}+2 \mathrm{O}_{2}$

Fig.6. Variation of normalized detonation velocity with $D_{\mathrm{H}} / \lambda$ in $\mathrm{C}_{2} \mathrm{H}_{2}+2.5 \mathrm{O}_{2}+85 \% \mathrm{Ar}$ mixture in annular channels

Fig.7. Variation of normalized detonation velocity with $D_{\mathrm{H}} / \lambda$ in $\mathrm{C}_{2} \mathrm{H}_{2}+2.5 \mathrm{O}_{2}+70 \% \mathrm{Ar}$ mixture in annular channels

Fig.8. Variation of normalized detonation velocity with $D_{\mathrm{H}} / \lambda$ in $\mathrm{C}_{3} \mathrm{H}_{8}+5 \mathrm{O}_{2}$ mixture in annular channels

Fig.9. Variation of normalized detonation velocity with $D_{\mathrm{H}} / \lambda$ in $\mathrm{CH}_{4}+2 \mathrm{O}_{2}$ mixture in annular channels

Fig.10. Smoked foil results for both stable (a) and unstable (b) mixtures at the condition well within the limits in the annular channel

Fig.11. Smoked foils results for the stable mixture at the conditions outside the limits $\left(\mathrm{C}_{2} \mathrm{H}_{2}+\right.$ $\left.2.5 \mathrm{O}_{2}+85 \% \mathrm{Ar}, P_{0}=14 \mathrm{kPa}, w=3.2 \mathrm{~mm}\right)$

Fig.12. Smoked foils results for the unstable mixture at the conditions outside the limits $\left(\mathrm{C}_{3} \mathrm{H}_{8}+5 \mathrm{O}_{2}, P_{0}=1 \mathrm{kPa}, w=5.9 \mathrm{~mm}\right)$ 


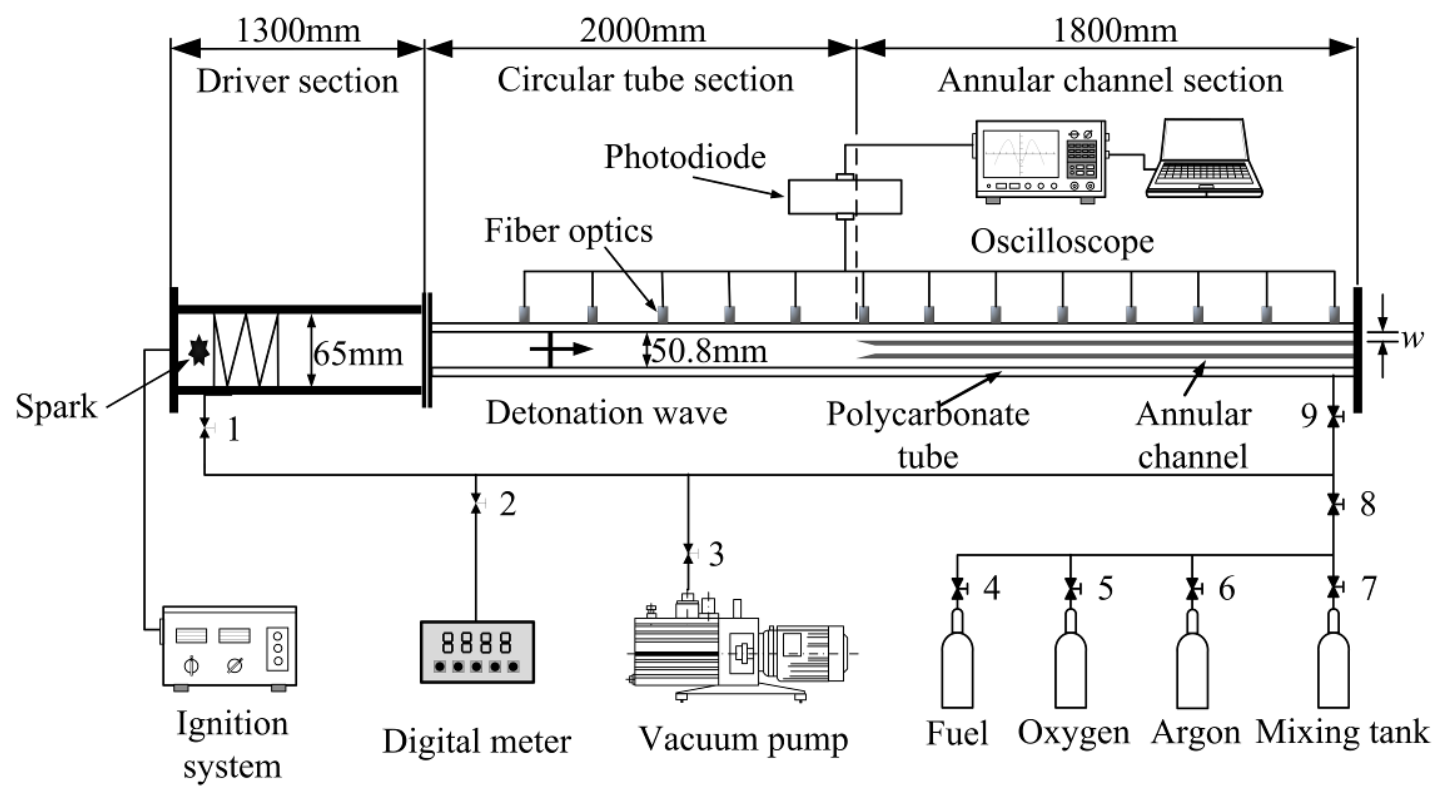

(a)

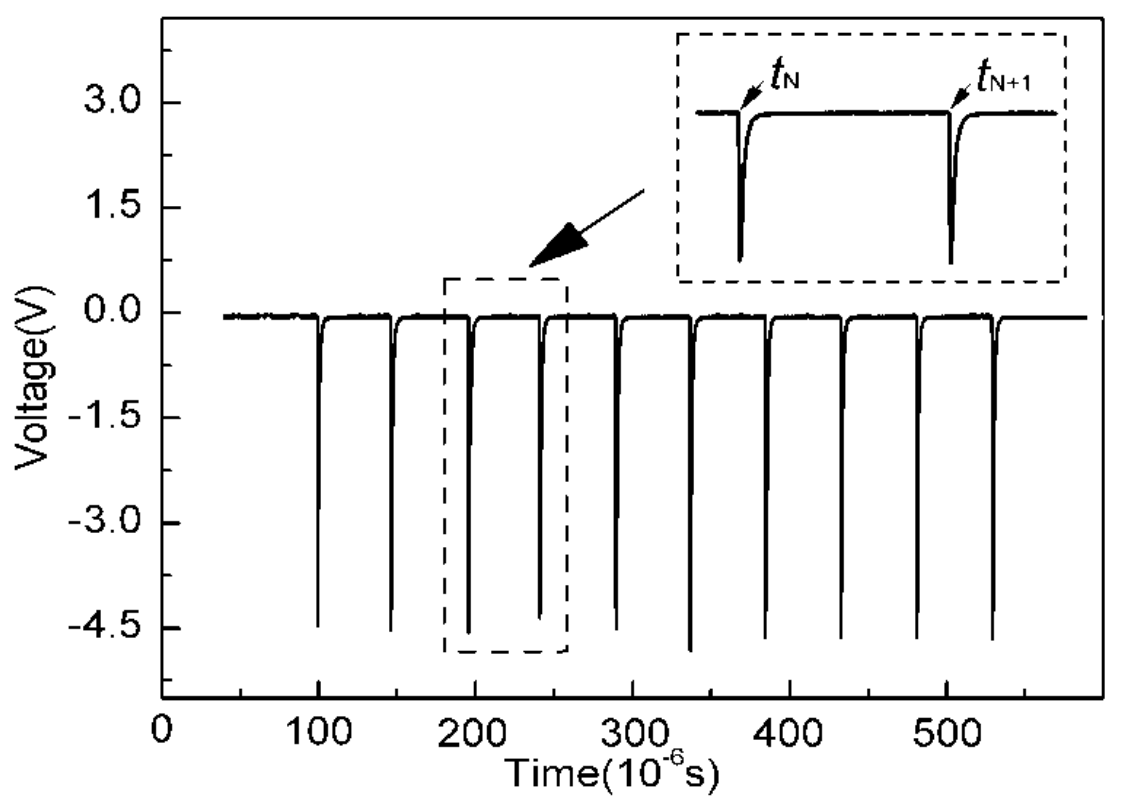

(b)

Fig. 1

Page 18 of 29 


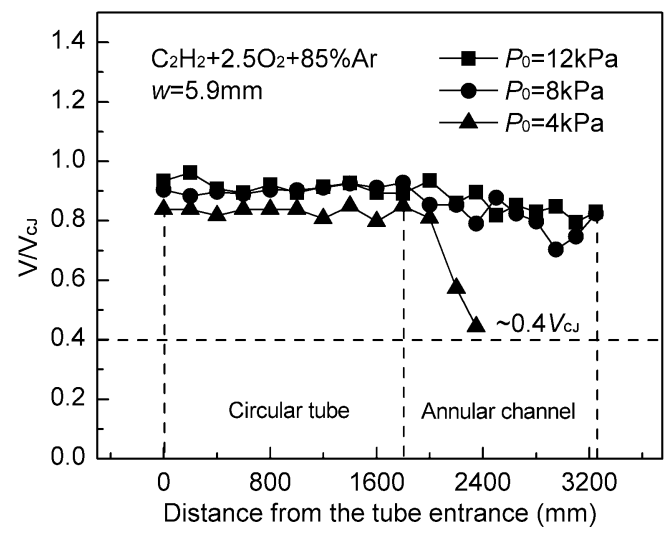

(a)

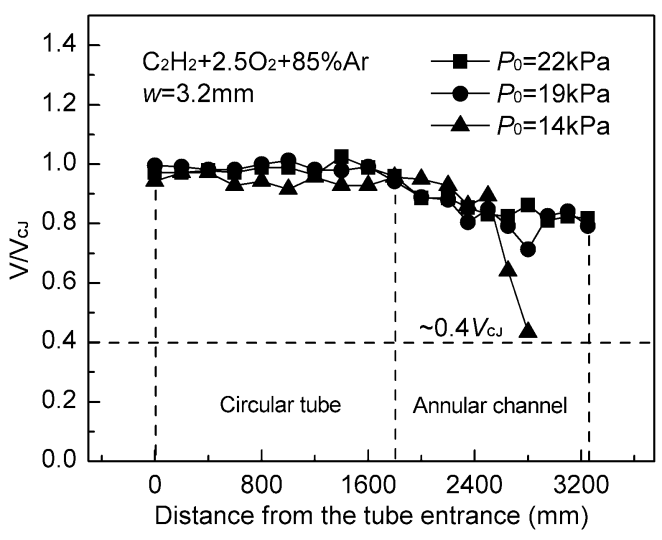

(b)

Fig. 2

Page 19 of 29 


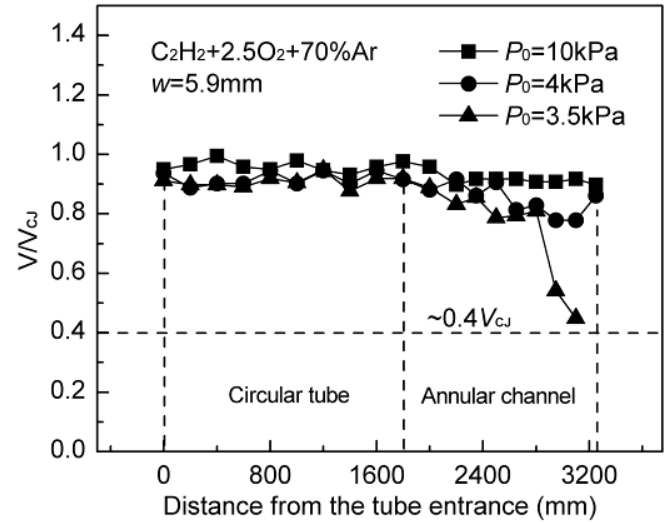

(a)

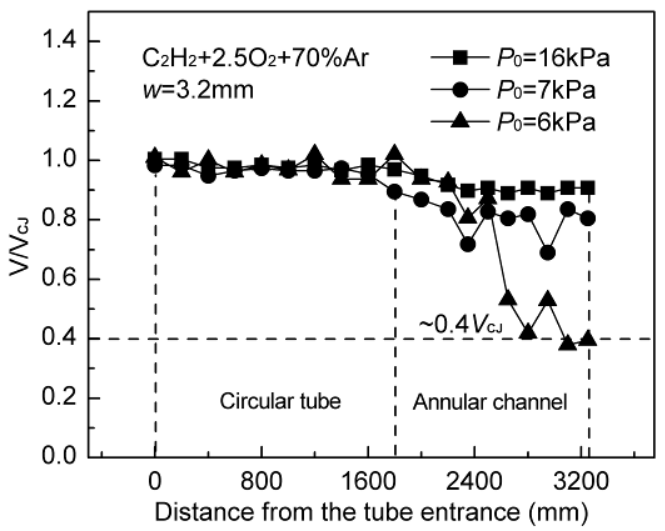

(b)

Fig. 3 


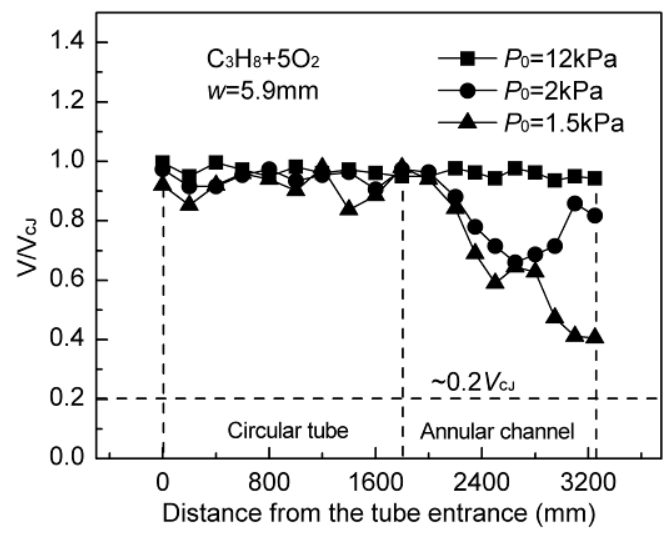

(a)

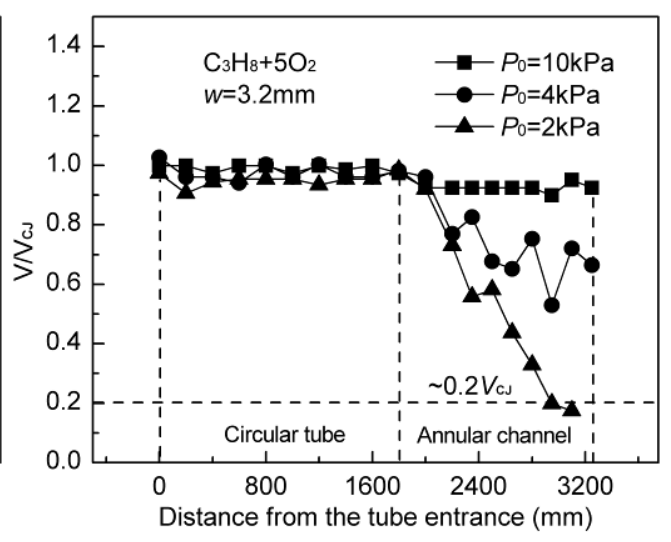

(b)

Fig. 4

Page 21 of 29 


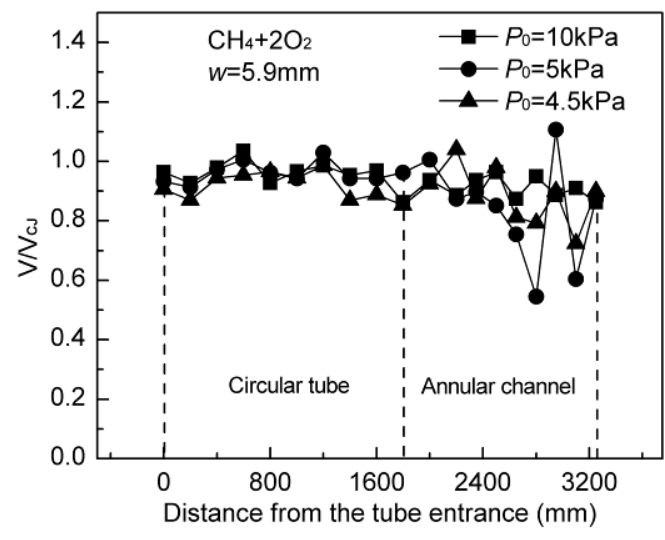

(a)

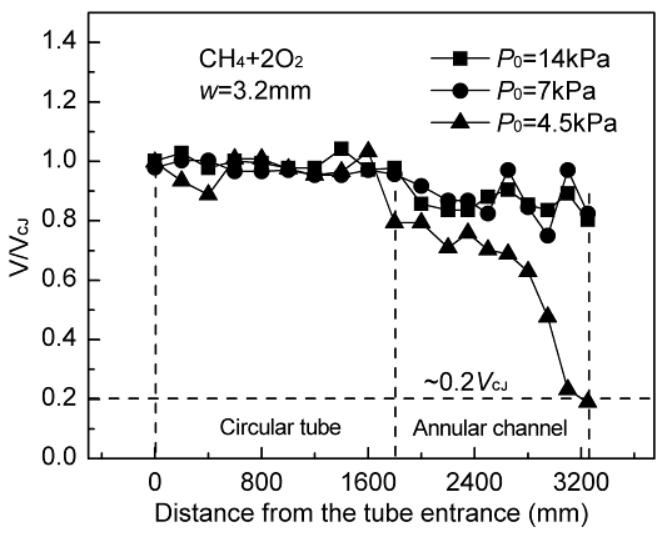

(b)

Fig. 5

Page 22 of 29 


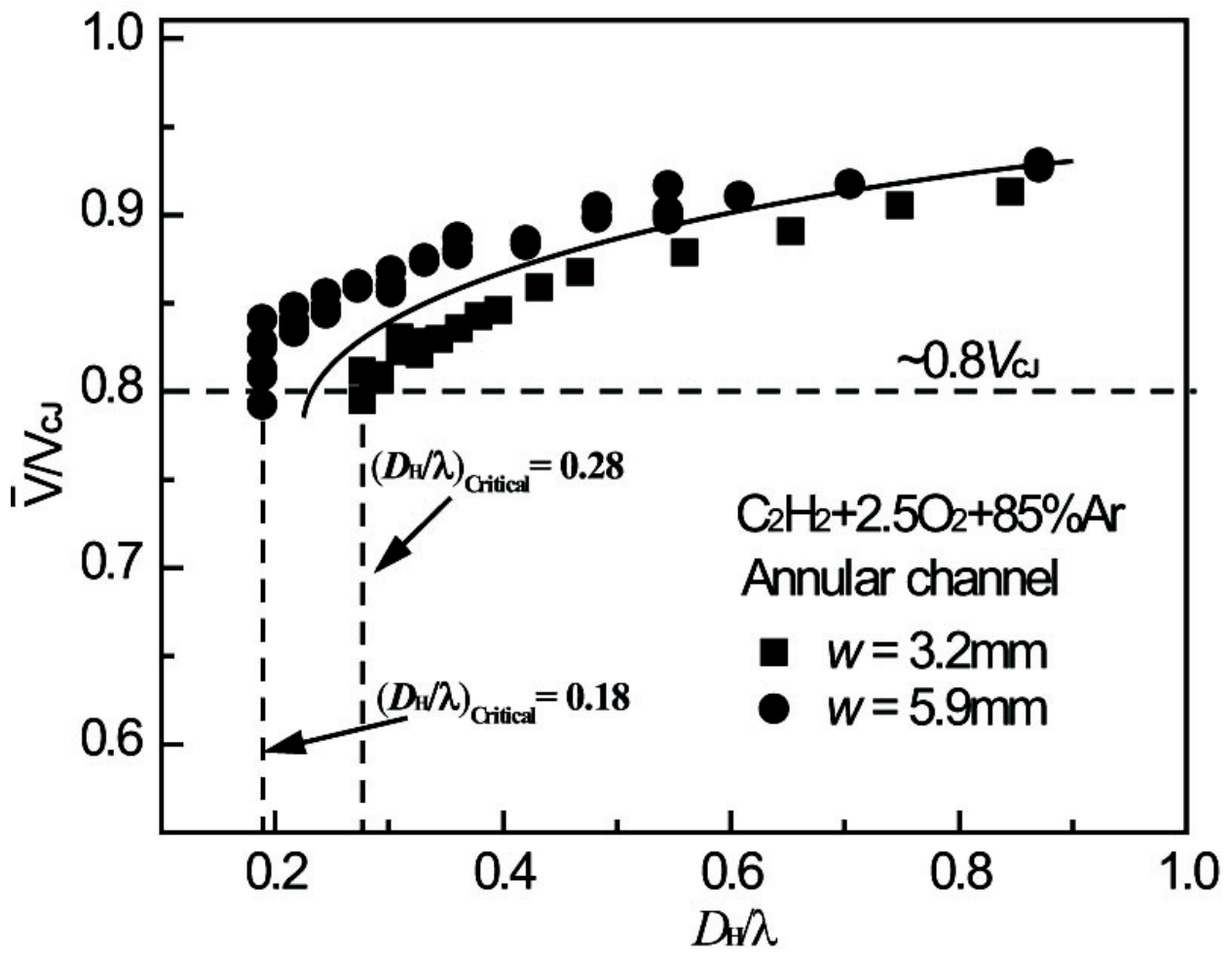

Fig. 6 


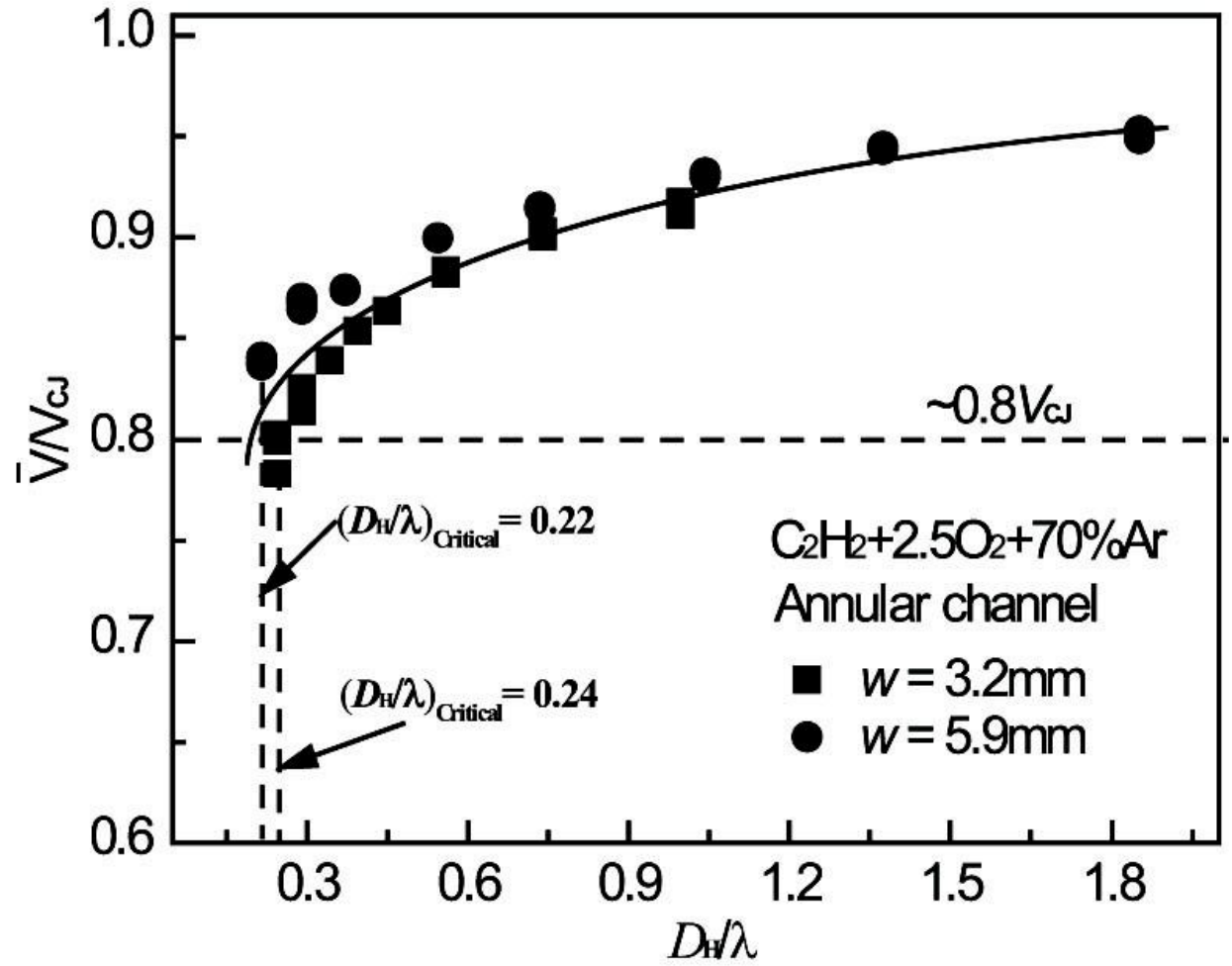

Fig. 7 


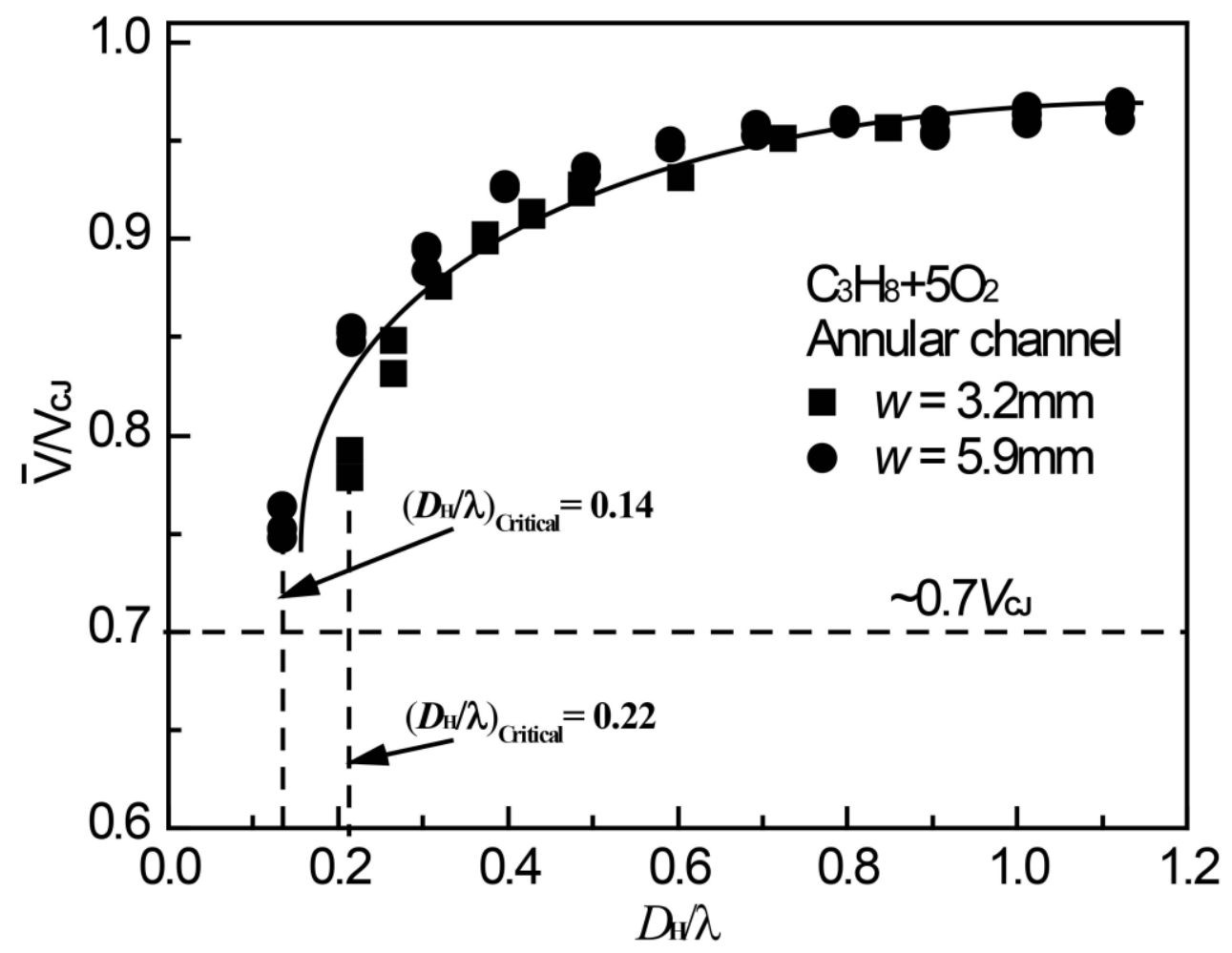

Fig. 8 


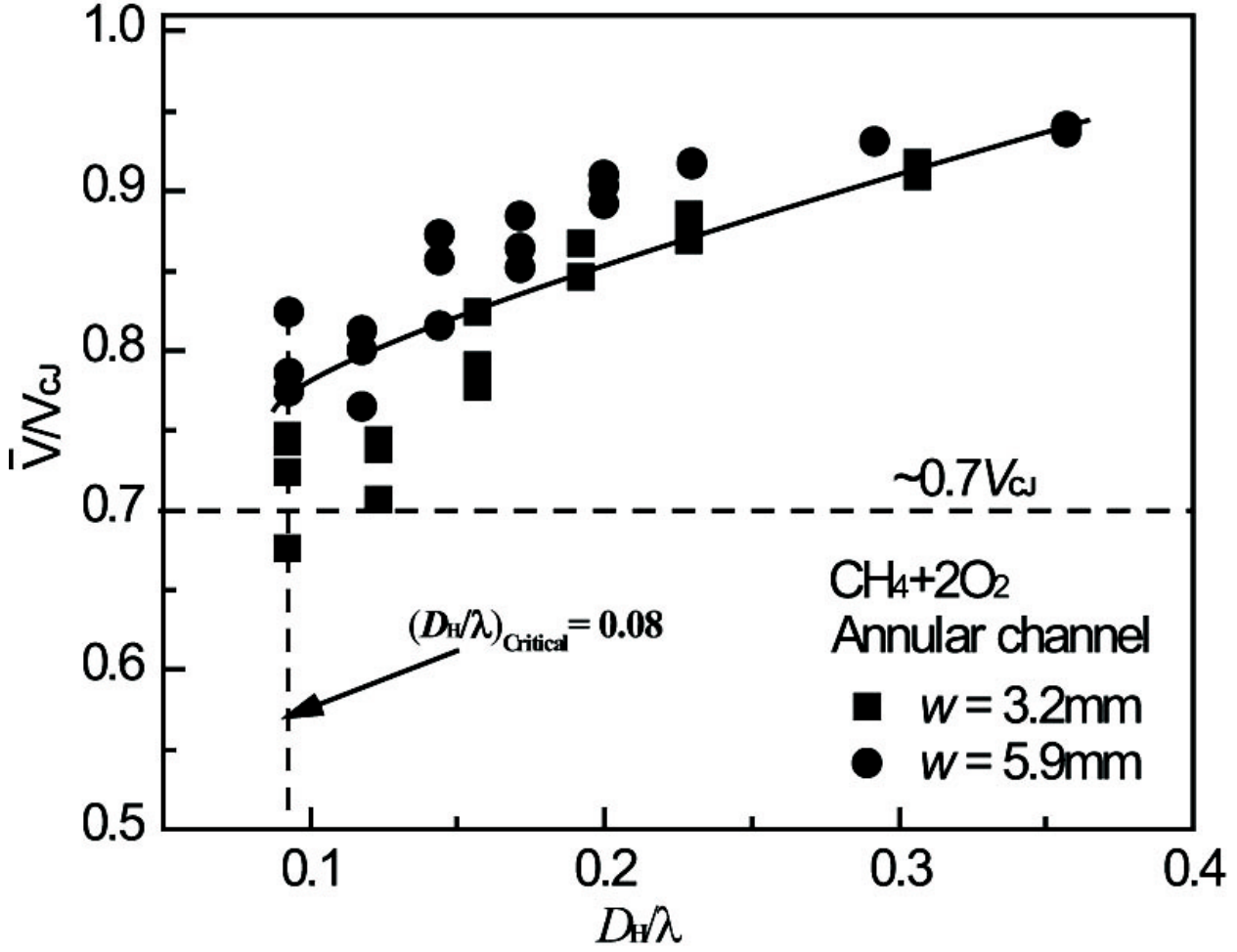

Fig. 9 


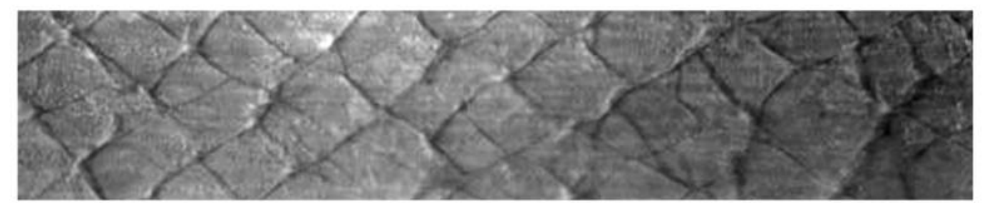

$12 \mathrm{kPa}$

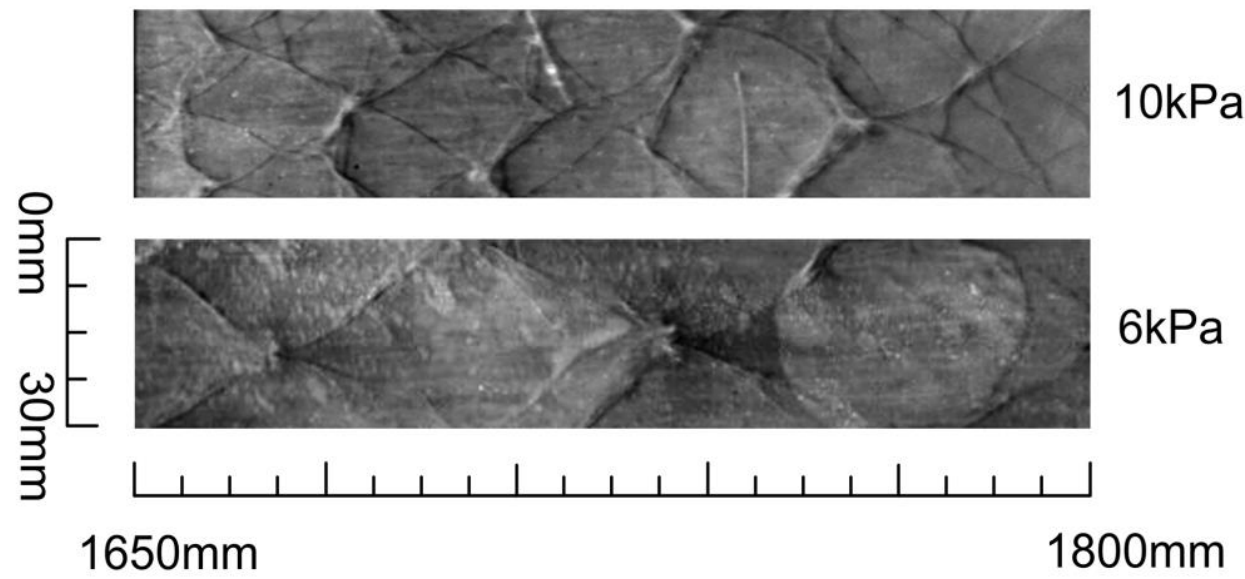

Distance from the annular channel entrance

(a) $\mathrm{C}_{2} \mathrm{H}_{2}+2.5 \mathrm{O}_{2}+70 \% \mathrm{Ar}, w=5.9 \mathrm{~mm}$

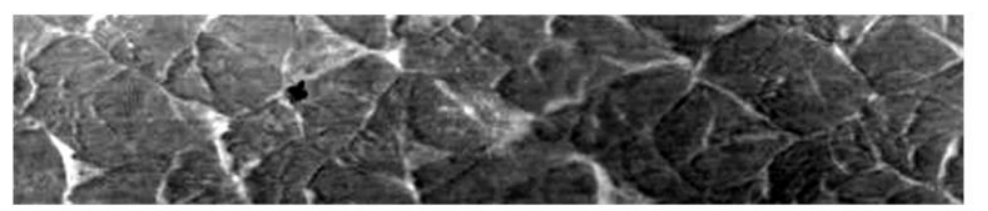

$25 \mathrm{kPa}$

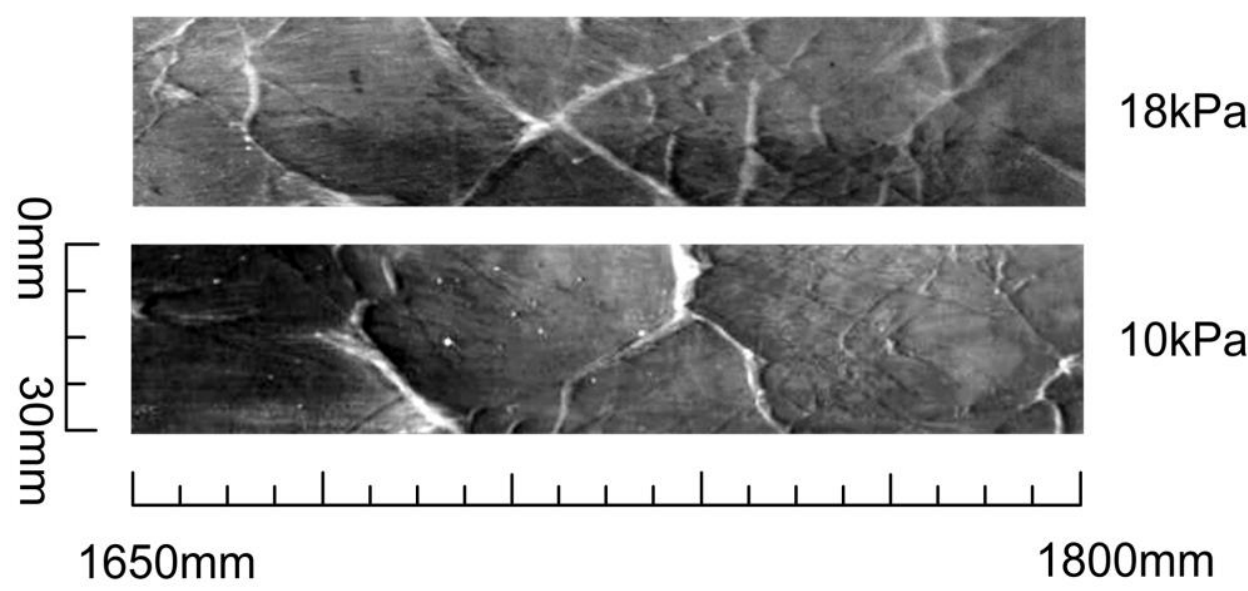

Distance from the annular channel entrance

(b) $\mathrm{CH}_{4}+2 \mathrm{O}_{2}, w=5.9 \mathrm{~mm}$

Fig. 10 

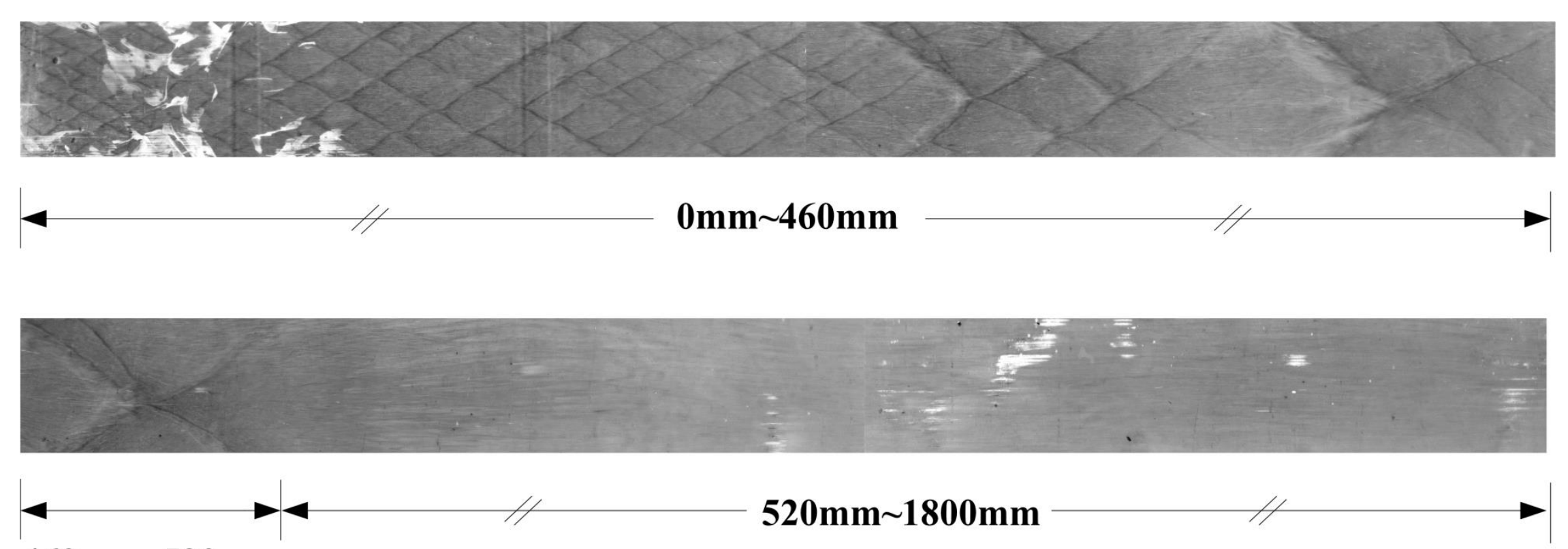

$460 \mathrm{~mm} \sim 520 \mathrm{~mm}$

Distance from the annular channel entrance

Fig. 11 

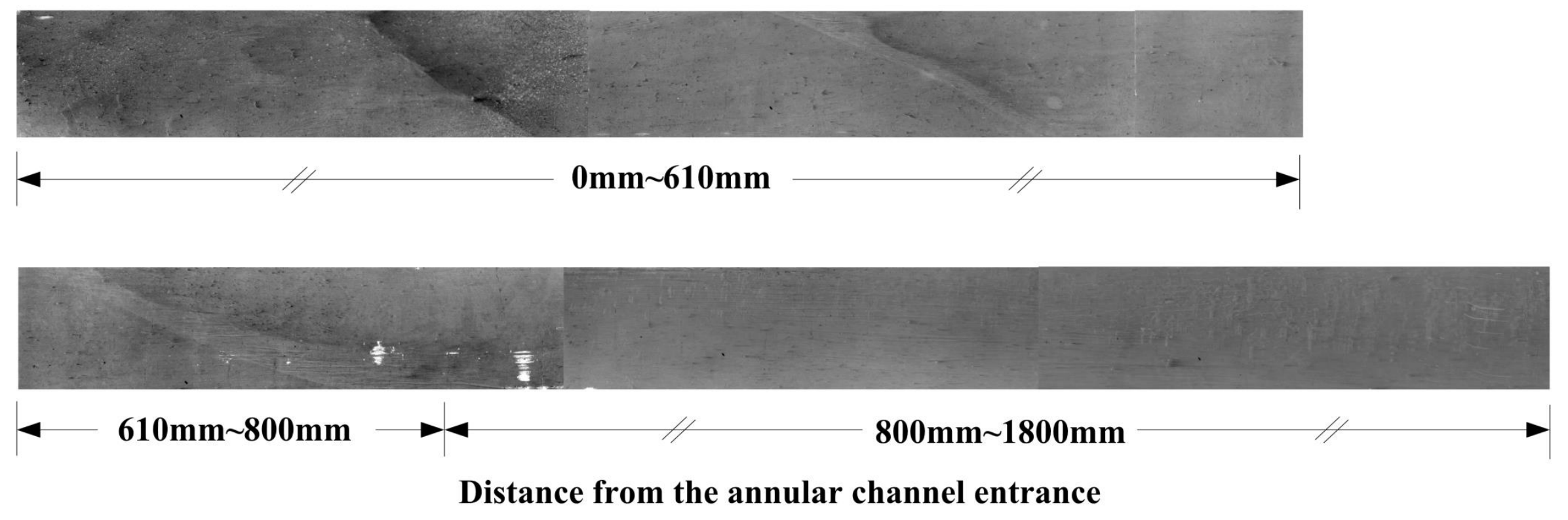

Fig. 12 